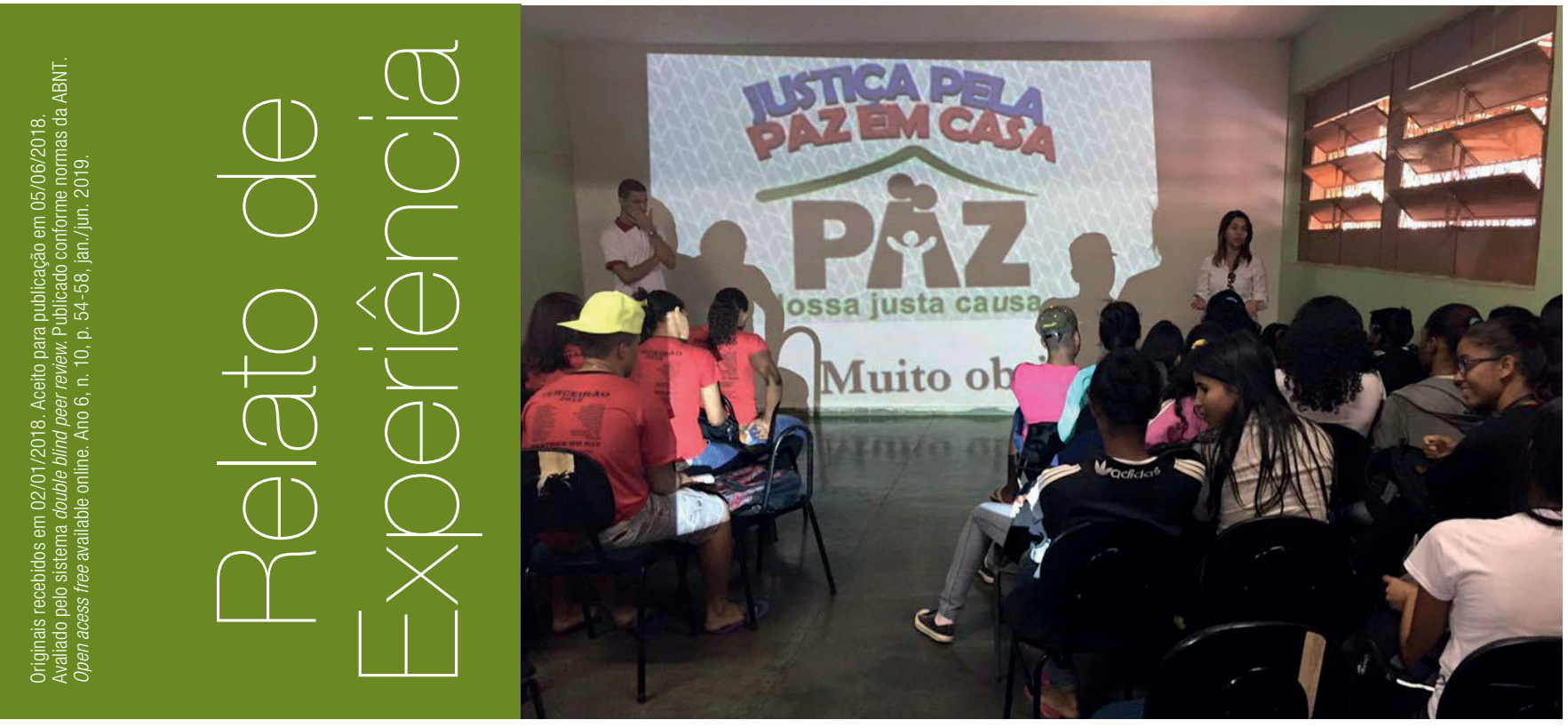

\title{
Programa Serviço de Assistência Jurídica Gratuita Itinerante - S.A.J. Itinerante: acesso à justiça além das fronteiras
}

Monique Araújo Lopes e Oliveira - moniquelaraujo@hotmail.com ${ }^{1}$ Ionete de Magalhães Souza - ionete@mail.connect.com.br ${ }^{2}$

\section{RESUMO}

Este relato apresenta as principais experiências vivenciadas no âmbito do Programa de Extensão Serviço de Assistência Jurídica Gratuita Itinerante - S.A.J. Itinerante. Desenvolvido pelo Curso de Direito da Universidade Estadual de Montes Claros - Unimontes. 0 Programa constitui ferramenta para viabilização do acesso à justiça a quem necessitar, por meio da difusão de informações jurídicas e da realização de palestras para os mais variados públicos, além da organização de Seminários e Congressos.

\section{PALAVRAS-CHAVE}

Itinerante. Assistência jurídica. Acesso à justiça. Cidadania.

\section{ABSTRACT}

The present report presents the main experiences lived within the scope of the Extension Program Free Legal Assistance Service Itinerante - S.A.J. Itinerant. Developed by the Law Course of the

\footnotetext{
1 Assistente Social graduada pela Unimontes e acadêmica do Curso de Direito da Unimontes

2 Professora Mestre e Doutora em Direito da Unimontes e Coordenadora do Programa Serviço de Assistência Jurídica Gratuita Itinerante - S.A.J. Itinerante, no período de 2002-2017
} 
State University of Montes Claros - Unimontes, the Program is a tool to facilitate access to justice for those most in need, through the dissemination of legal information, the holding of lectures for the most varied public, and the organization of Seminars and Congresses.

\section{KEYWORDS}

Itinerant. Legal assistance. Access to justice. Citizenship.

\section{Introdução}

0 modelo contemporâneo de universidade transformadora traz a Extensão Universitária como um processo educativo, científico e cultural indissociável do Ensino e da Pesquisa. Compõe-se, assim, um tripé que promove a aproximação entre a Universidade e a Sociedade, bem como viabiliza a democratização do conhecimento construído nas diversas áreas.

Compondo essa nova estética de universidade transformadora é que se destaca a atuação do Programa de Extensão Serviço de Assistência Jurídica Gratuita Itinerante - S.A.J. Itinerante, que há 16 anos realiza suas atividades. Dentre elas, há palestras, consultorias jurídicas itinerantes e promoção de seminários e congressos, dentre outras ações que fazem do Programa uma ferramenta de promoção do acesso à justiça e à cidadania. Também é um meio de atuação da Unimontes, através do Curso de Direito, na consecução dos fins relacionados às atividades de extensão da Universidade.

\section{S.A.J. Itinerante: de projeto a programa}

0 Programa pertence ao Curso de Direito da Unimontes e à Pró-Reitoria de Extensão. Além de atuar no município de Montes Claros, na zona urbana e rural, também desenvolve suas atividades nas demais localidades norte-mineiras, sendo requisitado, inclusive, por outras localidades mais distantes.

0 S.A.J. Itinerante como Projeto foi institucionalizado em 2002, pelo Conselho de Ensino, Pesquisa e Extensão - Cepex da Unimontes, conforme Resolução n. 59. Com a execução do projeto e ampliação das atividades, foi transformado em 2008, em Programa, nos termos da Resolução n. 238.

\section{$3 \bigcirc$ acesso à justiça sem fronteiras}

É evidente a necessidade de garantia e efetivação de meios que propiciem o acesso à justiça a todos os cidadãos, garantido de modo igualitário a chamada paridade de armas.

Contudo 0 Estado, apesar de ser o garantidor primeiro das normas constitucionais, dentre as quais 0 acesso à justiça gratuita, não consegue sozinho a plena satisfação de tais preceitos, sendo a sociedade civil chamada a atuar na efetivação dos direitos fundamentais (SOUZA, 2013).

É com base nisso que se firma o S.A.J. Itinerante, cumprindo seu papel no aperfeiçoamento da justiça, na medida em que a aproxima das pessoas que não conhecem seus direitos. A perspectiva é de romper e/ou minimizar os aspectos que dificultam as possibilidades do cidadão comum de ser bem servido juridicamente.

Através das atividades realizadas pelo S.A.J. Itinerante também são devolvidos à comunidade, não só local, como de outras regiões, o conhecimento e a teoria construídos no ensino da Universidade. Isso possibilita a democratização do conhecimento em diversas áreas do Direito.

Em suma, as atividades propostas e desenvolvidas pelo Programa demonstram seu caráter de Extensão Universitária, bem como de ferramenta aliada ao processo educativo, cultural e 
científico. Assim, articulam-se a Extensão e, de modo conjunto, o Ensino e a Pesquisa de forma indissociável, possibilitando uma parceria transformadora entre Universidade e Sociedade.

No Programa, as orientações são dadas por professores capacitados, que são Advogados devidamente inscritos na Ordem dos Advogados do Brasil em Minas Gerais (OAB/MG) e atuantes nas diversas áreas do Direito. A partir disso os acadêmicos voluntários do S.A.J. Itinerante levam para as comunidades as informações necessárias. 0 objetivo é que possam tê-las como ferramentas eficazes na solução de seus problemas.

Ainda, as atividades realizadas pelo Programa não se limitam à consultoria. Dessa forma, se surgirem demandas por atendimentos, elas são analisadas e encaminhadas para o Núcleo de Prática Jurídica da Unimontes, onde os acadêmicos que realizam o estágio supervisionado obrigatório podem dar andamento ao caso.

Por último, é primordial destacar o trabalho em rede realizado em parceria com demais órgãos. Ele se dá no encaminhamento do público-alvo para instituições que possam proporcionar melhores soluções à pretensão dos sujeitos atendidos, como as Defensorias Públicas Estadual e Federal, os demais Núcleos de Práticas Jurídicas da região, os Centros de Referência em Assistência Social, Conselho do Idoso etc.

\section{Principais atividades realizadas e resultados alcançados}

Com relação às principais atividades do Programa, destaca-se inicialmente 0 atendimento jurídico, que se concretiza em dois momentos: 0 primeiro é chamado de Informação Cidadã, na qual os acadêmicos divulgam, através de abordagem direta e distribuição de folders 0 Programa; 0 segundo momento é 0 atendimento propriamente dito, realizado pelos acadêmicos mais experientes, orientados pelos Professores.

Os atendimentos acontecem, na maioria das vezes, em finais de semana e as principais demandas atendidas envolvem, especialmente, o Direito de Família e 0 Direito Previdenciário.

São realizadas também palestras educativas, ministradas por acadêmicos, após a produção de um projeto, elaborado pelo acadêmico responsável pela palestra e orientado e corrigido por um Professor/Advogado específico. 0 público-alvo dos projetos é o ensino fundamental e médio de escolas das redes pública e privada, bem como o público atendido por órgãos da Assistência Social Municipal, como os CRAS e os CREAS.

Outrossim, o S.A.J. Itinerante também promove seminários e congressos acadêmicos, organizando ou sendo parceiro.

No que concerne à abrangência do Programa, em termos geográficos, envolve, especialmente, o Norte de Minas Gerais e todo o alcance dos câmpus da Unimontes. Isso representa quase um terço do Estado, sendo que já foram prestados serviços nas cidades de Jequitaí (de 2009 até 2016, no evento "Dia da Cidadania"), São Francisco, Brasília de Minas, Grão Mogol, Francisco Sá, São João da Ponte, Bocaiúva, Salinas, Capitão Enéas, Janaúba, Januária, Bonito de Minas, Mirabela, Montalvânia, Navarro, Varzelândia, Pai Pedro, Buritizeiro, Patis, São João do Pacuí, Minas Novas, Itacambira, além de Montes Claros e seus Distritos (Zona Rural), como Claraval, Ermidinha, Mandacaru, Miralta e Nova Esperança; além de comunidades quilombolas da região, como a pertencente ao município de São João da Ponte, denominada Comunidade Agreste. E até a cidade de Mortugaba, na Bahia, com palestra educativa. Nesses 16 anos de atividades realizadas pelo Programa cerca de 50 mil pessoas foram beneficiadas diretamente.

0 número de acadêmicos voluntários envolvidos supera 300 do Curso de Direito, ao longo de todo o tempo, sem contar outros acadêmicos esporádicos de cursos diversos da Unimontes, como Serviço Social. 


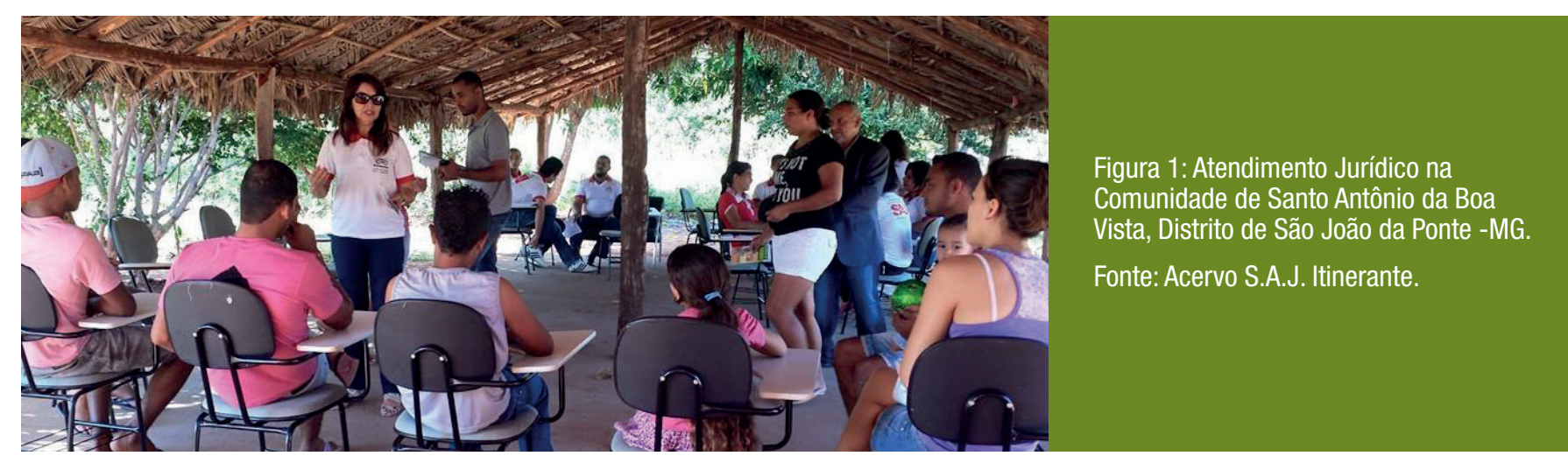

Por fim, dentre outros prêmios e homenagens, ressalta-se que o S.A.J. Itinerante foi premiado nacionalmente pelo "Programa de Extensão Universitária" (Proext) do Ministério da Educação, no ano de 2013, com o maior prêmio nacional, correspondente a $R \$ 150$ mil, que foram empregados em bens e serviços acadêmico-sociais.

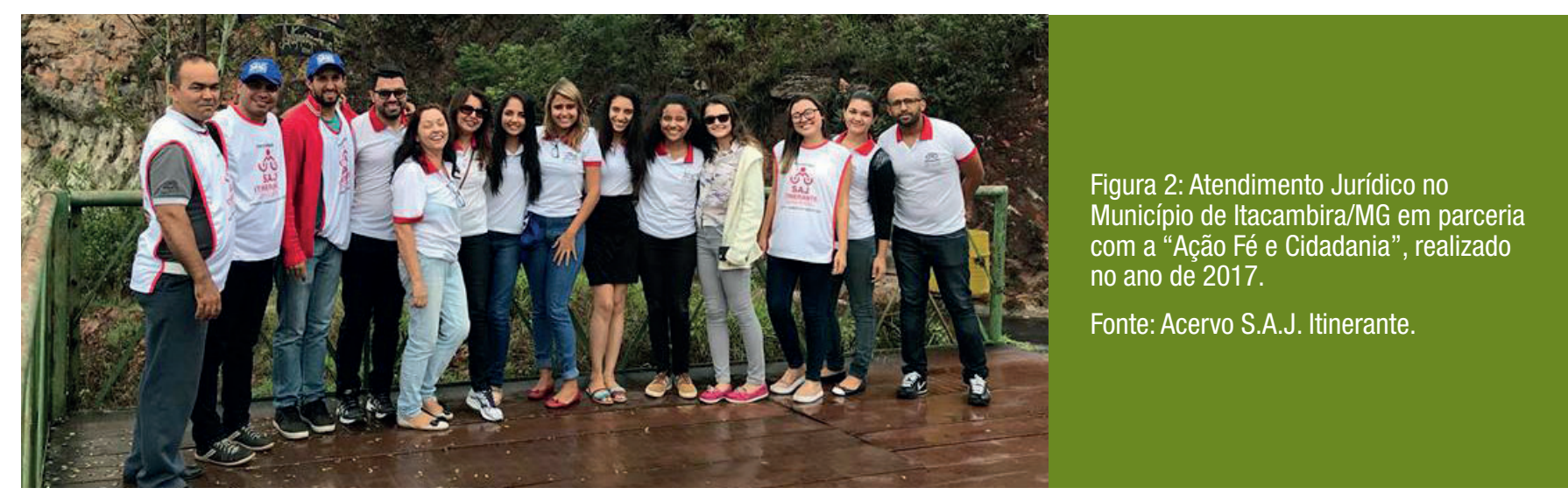

\section{Considerações finais}

0 Programa S.A.J. Itinerante já beneficiou pessoas de uma grande área geográfica em Minas Gerais. Os acadêmicos voluntários do curso de Direito, e outros acadêmicos esporádicos de cursos diversos, são orientados por seis professores, atuantes em diversas áreas do conhecimento jurídico.

As palestras educativas são atividades comumente realizadas e solicitadas ao Programa por escolas e outras entidades, a exemplo: a Polícia Militar de Minas Gerais, a OAB/MG, as Igrejas, os Centros de Referência em Assistência Social de municípios etc, cujas temáticas mais solicitadas são: "Discussões sobre o Estatuto do Idoso", "0 Estatuto da Pessoa com Deficiência e a educação inclusiva", "0 empoderamento de crianças negras e o direito à igualdade", "Os Direitos da Criança e o âmbito da Internet" e "Violência doméstica: Justiça pela Paz em Casa".

Por fim, o S.A.J. Itinerante segue buscando o aperfeiçoamento do atendimento ao público e oportunizando 0 acesso à justiça ao cidadão, sendo, portanto, uma ferramenta de viabilização da cidadania plena.

\section{Referências}

BRASIL. Constituição da República Federativa do Brasil: promulgada em 5 de outubro de 1988. Disponível em: http://www.planalto.gov.br/ccivil_03/constituicao/ constituicaocompilado.htm. Acesso em: 29 dez. 2017. 
SOUZA, Ionete de Magalhães. Perícia genética paterna e acesso à justiça: uma análise constitucional. 3. ed. Leme: J. H. Mizuno, 2013.

. Programa S.A.J. Itinerante (2002-2012): é dez! Montes Claros (MG):

Unimontes, 2012. 